some things we must have, and we do not want to be driven back to Germany for them, but our manufacturers must wake up.

These glass squares were for mounting marine animals in formalin under large watch-glass coversa mode of exhibition that had proved effective and durable. Mr. Renouf also explained a method of cutting large holes in glass with a screw-tap, and recommended Steubner's waterproof ink for injecting fine blood-vessels. Mr. Rowley described an exhibit for children in the Exeter Museum; Mr. Lowe showed a revolving frame for exhibiting coins; $\mathrm{Mr}$. Carline discussed open-air folk-museums; and Prof. Myres advocated the preservation of objects rapidly changing under present conditions. Profs. Poulton, Sollas, Bourne, and Bowman vied with Messrs. Balfour, Hogarth, and Leeds in demonstrating the riches and methods of their respective museums and departments.

Sir William Martin Conway was elected president of the association for the coming year, and the new secretary is Dr. W. M. Tattersall, Manchester Museum

\section{THE NORTH-EAST COAST INSTITUTION OF ENGINEERS AND SHIPBUILDERS.}

WITH the view of honouring some of those who helped to win the war, of recording the work done on the North-East Coast for the war, and of commemorating those members of the institution who fell during the war, the North-East Coast Institution of Engineers and Shipbuilders held a Victory meeting at Newcastle-upon-Tyne on July 8-iI. The honorary fellowship of the institution was presented to the Hon. Lady Parsons, Marshal Foch, Sir David Beatty, Sir Douglas Haig, Lord Weir, and Sir Joseph Paton Maclay.

Lady Parsons read a paper on women's work in engineering and shipbuilding during the war. The record of skilled work done by women given in the paper controverts the impression which many people have that women are only capable of doing repetition work on fool-proof machines. There is no doubt that many women developed great mechanical skill and a real love of their work. The engineering industry is again barred to women by an agreement made between the Treasury and the trade unions, with the result that women wealth-producers are scrapped. The meeting agreed with Lady Parsons's condemnation of the Labour Party, which, while demanding full political equality for women and their right to sit in the House of Lords and to practise at the Bar and as solicitors, will not grant to women equality of industrial opportunity.

Mr. A. H. J. Cochrane gave a short record of the work of the principal industries of the North-East Coast during the war. There have been two important developments in marine engineering for which the war period is partly responsible. These are the increased and increasing use of speed-reduction gearing in turbine-driven sets-the output of gearing by one firm during $1915^{-18}$ amounted to 2,830 , ooo shafthorse-power-and, secondly, the high standard of accuracy which has been reached in the design, construction, and installation of turbine machinery. This efficiency has enabled the Admiralty to dispense with exhaustive preliminary trials of machinery. Probably the most remarkable case cited in the paper is that of the destroyer Nonsuch, which, under conditions of emergency, actually raised her full power within seven minutes of leaving the piers. It is also of interest to note that the total stoppages of work due to raids and raid-alarms amounted to 47 hours 24 minutes during the whole war period of 221 weeks. The total output was III0 vessels, with a tonnage of $3,324,912$, which gives an average of five ships per week.

A long paper on developments in aircraft design and application during the war was read' by Lord Weir. The section dealing with future developments is of special interest. An outbreak of war should see us with the very best designs of engines and aircraft, tried and tested, and with a manufacturing nucleus on which war production may be readily expanded. In civil aviation the more immediate problems of international and domestic aerial legislation have been provisionally solved by the International Aerial Convention and by the Civil Aviation Act, and it is gratifying that in both these directions Great Britain has taken the lead and shown the way. In another direction much remains to be carried out quickly. Wre possess fleets of aircraft of trustworthiness and of great performance possibility, but our navigational facilities are still almost non-existent, and herein lies one of the main fields of action of our new Department of Civil Aviation. The two qualities of out standing merit in the new form of transport are speed and independence of action as against land transport requiring roads or rails. Speed in transport is associated with high cost, and speed will always command a high value. Early action should be taken in regard to a few main routes, especially in countries with equable weather conditions, and in new countries backward in rail development. Two such main routes would be Egypt to India, and Egypt to South Africa.

Lt.-Com. Norman Wilkinson gave some interesting particulars regarding his methods of dazzle-painting of ships, from which it appears that the object was not to secure invisibility, but to perplex submarines in the attempt to determine the precise course of the "dazzled "ship. The author, who is a marine painter of long experience, does not consider it possible to secure invisibility at sea. Success in submarine attack depends upon the attaining of a position which enables the attack to be made, and if a submarine once fails to secure the favourable position it is not likely to have a second opportunity. Reports from other ships bear striking testimony to the value of dazzle-painting :- "The vessel, at a distance of two or three miles, appeared as a wreck." "At four miles' distance I decided it was a tug towing a lighter." "I was on the point of stopping my engines and going full soeed astern-to avoid a collision, when I discovered that she was altering course to starboard. After passing the vessel it was almost impossible to say how she was steering."

Sir Dugald Clerk gave a paper on the limits of thermal efficiency in Diesel and other internal-combustion engines. The author considers that conditions all point to ultimate success in the construction of large gas-engine units composed of many cylinders geared to a common shaft. Large cylinder engines, such as had been developed in Germany before the war, do not permit of very large unit powers except at an extravagant weight and cost, and have no chance of competing with the steam turbine.

The paper on ship repairing by Messrs. M. C. James and L. E. Smith contains many interesting photographs and descriptions of extraordinary and urgent repairs executed during the war.

One of the most valuable papers of the meeting was that on science and its application to marine problems by Prof. J. C. McLennan. Reference is made to the development of listening devices in the submarine campaign. An echo method consists in the use of a beam of sound-waves used in a manner analogous to the use of a searchlight. If an object of sound such NO. 2594, VOL. IO3] 
as a submarine happens to come within the beam, the sound-waves are reflected and echo effects are obtainable. Success has been obtained in the picking up and closing on a submarine situated more than a mile away. A very important application of an electromagnetic effect is the Leader gear. A cable is laid on the bottom of the sea along the course of a narrow, tortuous channel leading into a harbour or through a minefield. Alternating currents passed through the cable can be detected on the ship by aural or visual indications, and by these indications the ship can be guided in safety in fog or darkness at speeds as high as twenty knots almost with as much precision as a tramcar over a railway. In water of suitable depth experience shows that it is a simple matter to apply this method for distances as great as fifty miles or longer.

Invisible signalling by polarised light, or ultra-violet and infra-red radiations has been employed where it is not advisable to use wireless communication. In wireless methods, by the use of oscillating thermionic valves especially, great progress has been made. Some extraordinary advances have been made in the measurement of the pressure of explosive waves. Changes which take place in $\mathrm{I} / \mathrm{IO0}, 000$ of a second have been recorded by the method suggested by Sir J. J. Thomson and applied by Mr. D. A. Keys, in which the inertia of a beam of cathode-ray particles is made use of; such rays are deflected by electrostatic and magnetic fields. The advances made in the production of helium warrant the opinion that, had the war continued after November II, I9I8, supplies of helium at the rate of $2,000,000$ cubic $\mathrm{ft}$. per month would have been produced within the Empire and the United States, and helium-filled aircraft would have been in service.

It is impossible within the limits of our space to deal adequately with Prof. McLennan's paper, both as regards what science has done in marine problems during the war and the large number of suggestions he makes regarding the application of what has been discovered to peace conditions.

\section{THE SIGNIFICANCE OF THE CEREBRAL CORTEX.}

$\mathrm{I}$ the series of Croonian lectures delivered at the Royal College of Physicians (June I2, I7, I9, and 24) Prof. Elliot Smith claimed that much of the obscurity concerning the meaning of the structure and functions of the cerebral cortex was due to the failure on the part of biologists and physicians to face the fact that the cortex is the organ of intelligence, and its chief significance of a psychical nature. It is no more possible to understand the cerebral cortex without recognising to the full its real purpose than it would be to explain the mechanism of an aeroplane if the investigator ignored the fact that the machine was made to fly.

The aim of these lectures was to discuss the means whereby the cerebral cortex acquired its supreme powers as the organ of intelligence. Dr. Henry Head's researches have given us a new vision of the meaning of nervous and mental processes, and have provided all workers in neurology with a new generalisation which compels them to review their own work in the light of the new illumination.

Much that was dark and unintelligible in the evolution of the cerebral cortex acquires a definite significance when the facts are examined in conjunction with the results of Dr. Head's clinical work and Prof. Sherrington's experimental researches.

The mammalian cerebral cortex, i.e. the neopallium, is the repository of past impressions, and these sensory dispositions profoundly modify the effect produced by the arrival of fresh impul ises. But Dr. Head has shown that, in addition, "the function of the cortex in sensation is to endow it with spacial relationships, with the power of responding in a graduated manner to stimuli of different intensities, and with those qualities by which we recognise the similarity or difference of objects" that appeal to the senses. On the other hand, the appreciation of the affective side of experience, the pleasantness or unpleasantness, and the crude awareness, are functions not of the cortex, but of the thalamus.

Since the discriminative functions of the cortex are particularly associated with the neopallium, which is found in a fully developed form only in mammals, the first inquiry must be directed towards an understanding of the psychical activities of the classes of vertebrates other than mammals; and from such investigations the nature of the circumstances which called the neopallium into being must be determined.

The fundamental fact in the evolution of intelligence is the significant part played by the sense of smell. In the primitive generalised vertebrate it provided the animal with information of varied kinds, but of direct and obvious psychological meaning, by which behaviour was determined in respect of most of those activities that affect the preservation of the individual and the species, namely, the search for food and the appreciation of its quality, the recognition of friends and enemies, as well as of sexual mates or rivals.

One factor which added to the dominating influence of smell and emphasised the directness of its appeal was the result of the circumstance that in an animal living in the water the sense of smell was very nearly akin to that of taste. When such an animal scented food it got, so to speak, a foretaste of the satisfying consummation of the experience when the food was seized, tasted, and swallowed with a feeling of intense satisfaction. The whole incident, from the first anticipation of the pleasure in store until the satisfying consummation; was under the dominance of the sense of smell, which became more and more intensely stimulated as the animal approached its auarry, until it culminated in the gratification and the appeal to the sense of taste. The affective tone of the sense of smell linked into a connected series all the incidents of this experience. and the psvchical integration that resulted formed the basis of the appreciation of time and space, of memory, the recall of the earlier incidents of the episode, and of anticipation, the endresult and the joyful consummation.

In the course of the pursuit of its prey the animal is subjected to the influence of manv other circumstances that appeal to the senses of vision, touch, pressure, temperature, etc., and affect the organs of equilibration; and the effects of all these events tend to become involved in the process of psychical integration. When such information as is collected by these other sense-organs acauire some biological significance to the animal, the visual, tactile, acoustic, and other sensory tracts make their way into the cortex in increasing numbers: and they stimulate the growth and differentiation of such special receptive areas as the hypopallium and neopallium. But this does not happen until the reptilian stage of development is reached.

When, attracted by its scent. the primitive vertebrate (such as an Elasmobranch fish) is impelled to pursue its prev, it circles about in the search because at first it has no more exact indication of the position of the object of its pursuit than the relative intensity of the odour as the nursuer moves about. But when it comes within visual range it acquires a more precise 